\title{
Superkapasitor Sebagai Penyimpan Energi Menggunakan Bahan Graphene
}

\author{
Faisal Irsan Pasaribu, Solly Aryza Lubis, Sasri Imam Panji Alam \\ Program Studi Teknik Elektro, Fakultas Teknik \\ Universitas Muhammadiyah Sumatera Utara (UMSU) \\ Jl. Kapten Muchtar Basri,BA No. 03 Medan Telp. (061) 6622400 ex. 12 Kode pos 20238 \\ e-mail: fais.irsan@umsu.ac.id
}

\begin{abstract}
Abstrak - Graphene adalah material baru yang ditemukan tahun 2004 secara sederhana oleh Andre Geim dan Konstantin Novoselov dengan menggunakan selotip yang direkatkan dengan karbon sehingga didapat lapisan dengan orde nanometer dari karbon tersebut. Graphene memiliki keunggulan mobilitas muatan yang tinggi dan memiliki konduktivitas listrik dan panas lebih baik dari material yang lain. Terutama dalam pembuatan super kapasitor yang dapat menyimpan muatan listrik. Penelitian ini Bertujuan untuk merancang superkapasitor dengan bahan dari graphene, activated carbon, polyurethane dan phosporic acid (H3PO4) dan menganalisi muatan listrik dan tegangan yang tersimpan selama pengecasan berlangsung, pada percobaan pertama pengecasan selama 1 menit dengan tegangan yang tersimpan 1,8volt dan tegangan akan habis selama 50:20,2 menit, maka voltase yang turun setiap detiknya $0.0006 \mathrm{v} / \mathrm{s}$ pada percobaan ke dua pengecasan selama 2 menit dengan tegangan yang tersimpan $1,8 \mathrm{volt}$ dan tegangan akan habis selama 58:28,8 menit, maka voltase yang turun setiap detiknya $0.0005 \mathrm{v} / \mathrm{s}$ pada percobaan ketiga pengecasan selama 60:24 menit dengan tegangan yang tersimpan 2volt dan tegangan akan habis selama 180:18,4 menit, maka voltase yang turun setiap detiknya $0.000185 \mathrm{v} / \mathrm{s}$ penelitian tersebut dapat disimpulkan bahwa superkapasitor memiliki muatan tegangan yang kecil tetapi memiliki daya simpan yang lama.
\end{abstract}

Kata kunci : Graphene, activated carbon, polyurethane, phosporic acid (H3PO4), super kapasitor, lama tegangan habis.

\begin{abstract}
Graphene is a new material that was discovered in 2004 simply by Andre Geim and Konstantin Novoselov using tape that is glued to carbon to obtain a layer of nanometer order from the carbon. Graphene has the advantage of high charge mobility and has better electrical and thermal conductivity than other materials. Especially in the manufacture of super capacitors that can store electrical charges. This study aims to design a supercapacitor with materials of graphene, activated carbon, polyurethane and phosporic acid (H3PO4) and analyzing the electrical charge and the voltage stored during the fitting, in the first experiment of 1 minute retention with 1.8 volt stored voltage and voltage discharged for 50: 20.2 minutes, then the voltage drops every second $0.0006 \mathrm{v} / \mathrm{s}$ in the experiment to two chargers for 2 minutes with 1.8 volts voltage and the voltage will be exhausted for $58: 28.8$ minutes, then the voltage drops every second $0.0005 \mathrm{v} / \mathrm{s}$, in the third experiment the 60:24 minute charger with 2 volt stored voltage and the voltage will run out for 180: 18.4 minutes, then the voltage drops every second $0.000185 \mathrm{v} / \mathrm{s}$. the research can be concluded that the supercapacitor has a small voltage charge but has a long shelf life
\end{abstract}

Keywords: Graphene, activated carbon, polyurethane, phosporic acid (H3PO4), supercapasitor, long voltage runs out

\section{PENDAHULUAN}

Pada era global ini, banyak sekali isu mengenai energi bermunculan, mulai dari sumber energi baru, terobosan energi alternatif, sampai pengembangan media penyimpanan energi. Media penyimpan energi yang dipakai pada alat elektronik sehari-hari adalah baterai dan kapasitor. Selama ini baterai memang dianggap efektif untuk menjadi sumber daya bagi alat yang membutuhkan voltase rendah. Namun, terdapat kelemahan jika sering dipakai maka baterai akan mengalami voltage drop.

\section{TINJAUAN PUSTAKA}

Adanya super kapasitor yang dipasang pada baterai akan meningkatkan performa dan umur pakai baterai (Rahman Faiz Suwandana, 2015). Salah satu material yang banyak dikembangkan saat ini adalah graphene. Graphene adalah salah satu keluarga unsur karbon, yang A. K. Geim dan K. S. Novoselov pada tahun 2004. graphene menjadi kenyataan dan menyebabkan Geim dan Novoselov dianugerahi Hadiah Nobel pada tahun 2010 (Geim AK, 2011). Dalam teknik ini, sepotong grafit mengalami pengelupasan pita berulang dan kemudian dipindahkan ke substrat. Jumlah lapisan kemudian dapat dievaluasi dengan 
metode yang berbeda dengan menggunakan mikroskop optik sederhana, spektroskopi Raman, mikroskop kekuatan atom dan / atau pemindaian mikroskop tunneling Metode preparasi ini masih membuat kristal kualitas tertinggi, namun hanya berguna untuk labscale percobaan dan prototyping karena tidak mungkin untuk meningkatkan proses (K. S. Novoselov, 2004). Penelitian ini membahas mengenai graphene superkapasitor dengan pengaruhnya terhadap lama pengisian charging, serta kapasitansi listrik material graphene, dan lama waktu daya yang terbuang.

\section{METODE}

Peralatan dan Bahan Penelitian

Bahan-bahan yang digunakan untuk perancangan Alat Penukar Botol Plastik Bekas Ditukar Dengan Air Minum Cup Mineral Berbasis Arduino ini yaitu :

1. Plat Aluminium dengan ketebalan $2 \mathrm{~mm}$ sebagai media kolektor.

2. Serbuk graphene sebagai elektroda.

3. Polyurethane resin sebagai perekat antara plat aluminium dengan graphene.

4. Acktivated Carbon (karbon aktif) di gunakan untuk penunjang daya serap energi listrik sebagai elektroda.

5. Phosphoric Acid (Asam Fosfat) sebagai elektrolit

6. Tisu digunakan sebagai separator untuk pemisah antara elektroda positif dan negatif.

7. Kabel digunakan sebagai kaki kolektor negatif dan positif.

8. Pembungkus Plastik sebagai cover superkapasitor.

9. Lakban sebagai lapisan kover kedua dan sebagai perekat superkapasitor.

10 Paku tembak sebagai penghubung kabel dan plat aluminium.

\section{Tahapan Perancangan Material}

Letakkan ice bath di atas hot plate magnetic stirrer, dan masukan jar ke dalam ice batch tersebut, kemudian masukan $50 \mathrm{ml}$ sulphuric acid kedalam jar, setelah satu jam masukan $1.5 \mathrm{gr}$ graphite powder stirrer sampai satu jam, setelah satu jam tambhkan $4.5 \mathrm{gr}$ pottasium permanganate secara perlahan lahan, karena akan ada reaksi kimia, suhu plat harus terjaga di bawah $20{ }^{\circ} \mathrm{C}$ dan stirrer selama 3 jam, angkat ice batch setelah 20 menit stirrer, setelah 3 jam stirrer, tambahkan $55 \mathrm{ml}$ air destilisasi ke dalam jar setetes demi setetes agar tidak terjadi reaksi kimia yang berlebihan yang mengakibatkan panas, sehingga kita harus mengatur suhu plat $50{ }^{\circ} \mathrm{C}$ untuk memulai proses oksidasi. Kemudian stirrer hingga berubah warna menjadi kecoklatan yang menunjukan pembentukan graphene oksida. Tambahkan lagi 100ml air destilisasi untuk mengoksidasi graphite jika ada yang tertinggal. Pada langkah terakhir, tambahkan $5 \mathrm{ml}$ hidrogen peroksida untuk menghilangkan jumlah potassium permanganat yang berlebihan atau dengan sederhana untuk menghentikan reaksi. Kemudian diamkan sampai serbuk graphene mengendap kebawah, setelah mengendap buang air tersebut dan kemudian di keringkan sehinggan menjadi bubuk graphene.

\section{HASIL DAN PEMBAHASAN}

Pengujian Lama Waktu Tegangan Listrik Habis

Pengujian ini di lakukan untuk mengetahui sebera lama waktu tegangan listrik yang akan habis di dalam super kapasitor graphene dalam waktu pengecasan yang berbeda-beda dengan ini akan di dapat nilai voltase yang akan turun di setiap menitnya. Di lihat pada tabel pengujian sebagai berikut :

Tabel 1 Data Pengujian Lama Waktu Muatan Listrik Habis

\begin{tabular}{|c|c|c|c|c|c|}
\hline NO & VOLTASE & WAKTU & NILAI & VOLTASE & LAMA WAKTU \\
$\begin{array}{c}\text { SUMBER } \\
\text { TEGANGAN }\end{array}$ & PENGECASAN & CAPASITANSI & $\begin{array}{c}\text { YANG } \\
\text { TERSIMPAN }\end{array}$ & $\begin{array}{c}\text { HABIS / } \\
\text { TERBUANG }\end{array}$ \\
\hline 1 & $3 V D C$ & 1 Menit & $230 \mu \mathrm{F}$ & $1.8 \mathrm{v}$ & $50: 20,2$ Menit \\
\hline 2 & $3 V D C$ & 2 Menit & $230 \mu \mathrm{F}$ & $1.8 \mathrm{v}$ & $58: 28,8$ Menit \\
\hline 3 & $3 V D C$ & $60: 24$ Menit & $230 \mu \mathrm{F}$ & $2 \mathrm{v}$ & $180: 18,4$ Menit \\
\hline
\end{tabular}

Dari tabel di atas dapat kita cari berapa voltase yang turun di setiap detiknya dan juga kita dapat mengetahui berapa tegangan yang terisi setiap detiknya, maka dapat kita tentukan dengan persamaan :

voltase yang turun setiap detik

$$
=\frac{\text { voltase yang tersimpan }}{\text { waktu habis /terbuang }}
$$

voltase yang terisi setiap detik

$$
=\frac{\text { voltase yang tersimpan }}{\text { waktu pengecasan }}
$$

Percobaan 1

$$
\begin{aligned}
& \text { voltase yang turun setiap detik }=\frac{1.8}{3012.2} \\
& =0.0006 \mathrm{v} / \mathrm{s}
\end{aligned}
$$


Percobaan 2

$$
\begin{gathered}
\text { voltase yang turun setiap detik }=\frac{1.8}{3496.8} \\
=0.0005 \mathrm{v} / \mathrm{s}
\end{gathered}
$$$$
\text { voltase yang terisi setiap detik }=\frac{1.8}{120}
$$

$$
=0.0015 \mathrm{v} / \mathrm{s}
$$

Percobaan 3

$$
\begin{aligned}
& \begin{array}{r}
\text { voltase yang turun setiap detik } \\
\qquad \begin{array}{r}
10810.8 \\
\text { voltase yang terisi setiap detik }
\end{array} \\
=0.000185 \mathrm{v} / \mathrm{2} \\
=0.00055 \mathrm{v} / \mathrm{s}
\end{array}
\end{aligned}
$$

Dari persmaan di atas dapat kita lihat semakin lama pengisian nya maka semakin lama tegangan yang akan habis di lihat dari percobaan 1, 2, dan 3 . maka kita bisa melihatnya dari grafik berikut

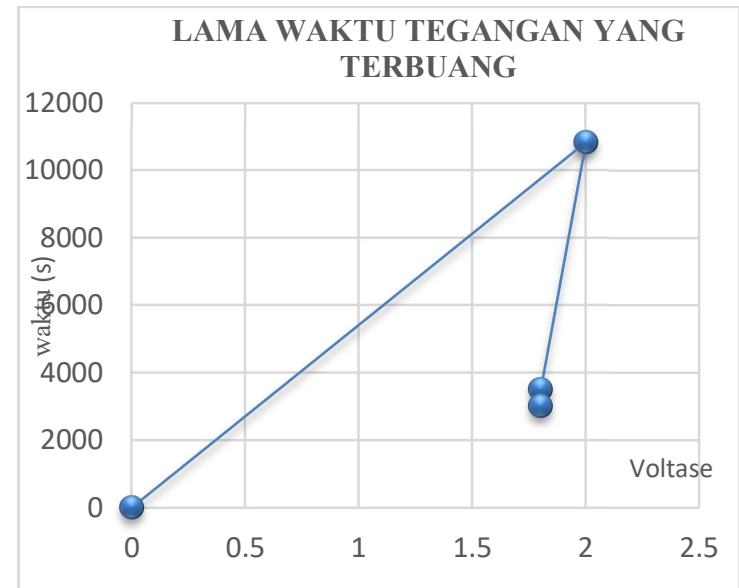

Gambar 1 Grafik tegangan yang terisi terhadap lama waktu tegangan yang terbuang

Dari grafik di atas dapat dilihat selisih dari percobaan 1, 2 adalah sekitar 0.0001 dan selisih 1,2 terhadap 3 adalah sekitar 0.0004. pada percobaan selanjutnya kita dapat melihat grafik 3.3 tegangan yang terisi setiap detiknya dan dapat kita lihat dari persamaan diatas jarak dan perbedaannya.

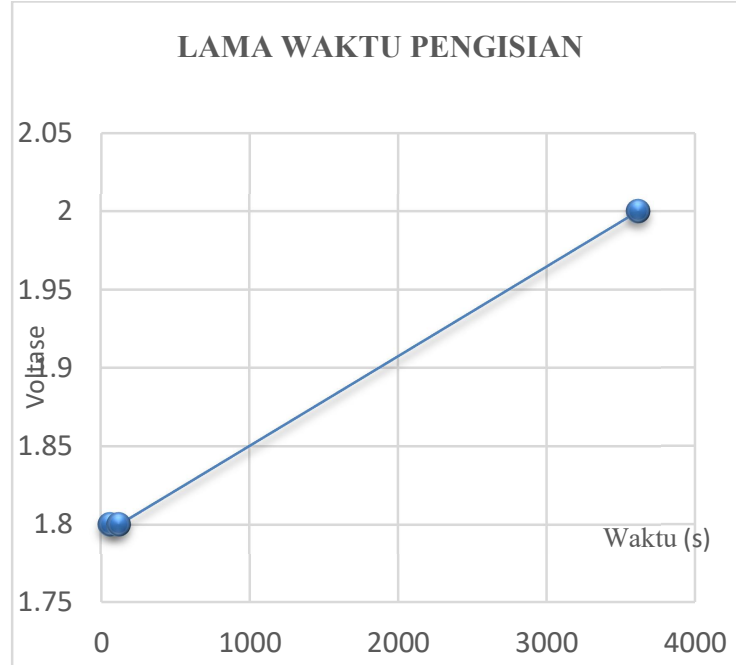

Gambar 2 Grafik tegangan yang terisi terhadap waktu pengisian

Pada grafik di atas dapat di lihat waktu dan tegangan yang terisi, pada 0 dan 1,8 terlihat jarak yang jauh dan semakin mengkerucut di angka 3614,4 detik dan mencapai 2 volt.

Pengujian Energi Listrik Yang Tersimpan Pada Super kapasior Graphene

Pengujian ini adalah untuk melihat nilai energi listrik yang tersimpan pada super kapasitor graphene dalam satuan joule dengan tegangan yang berbedabeda dapat di lihat dari tabel percobaan 1. untuk mencari nilai energi listrik yang tersimpan maka dapat kita cari dengan persamaan :

$$
E=\frac{c}{2}(v)^{2}
$$

$\mathrm{E}=$ energi listrik (joule)

$\mathrm{C}=$ muatan listrik ( Farad)

$$
\mathrm{V}=\text { tegangan }(\mathrm{V})
$$

Percobaan 1

$$
\begin{aligned}
E & =\frac{1}{2} C(V)^{2} \\
E & =\frac{1}{2} 230 \times 10^{-6}(1.8)^{2} \\
E & =\frac{0.0007452}{2} \\
E & =0.0003726 \text { joule }
\end{aligned}
$$


Percobaan 2

$$
\begin{aligned}
E & =\frac{1}{2} C(V)^{2} \\
E & =\frac{1}{2} 230 \times 10^{-6}(1.8)^{2} \\
E & =\frac{0.0007452}{2} \\
E & =0.0003726 \text { joule }
\end{aligned}
$$

Pada percobaan ke dua nilai w sama dengan nilai percobaan yang pertama di karenakan nilai tegangannya yang sama 1.8 Volt.

Percobaan ke 3

$$
\begin{aligned}
E & =\frac{1}{2} C(V)^{2} \\
E & =\frac{1}{2} 230 \times 10^{-6}(2)^{2} \\
E & =\frac{0.00092}{2} \\
E & =0.00046 \text { joule }
\end{aligned}
$$

Dari tiga percobaan di atas dapat di lihat perbedaannya dimana 1 dan 2 nilainya sama di karenakan nilai tegangannya juga sama dan berbeda dengan percobaan ketiga yang nilai tegangannya tidak sama dengan percobaan 1 dan 2, semakin besar tegangannya maka semakin besar juga nilai joule yang di dapat dan juga semakin besar nilai faradnya maka semakin besar juga nilai joule yang di dapat. Perbedaan ini dapat di lihat dari grafik terhadap nilai kapasitas super kapasitor.

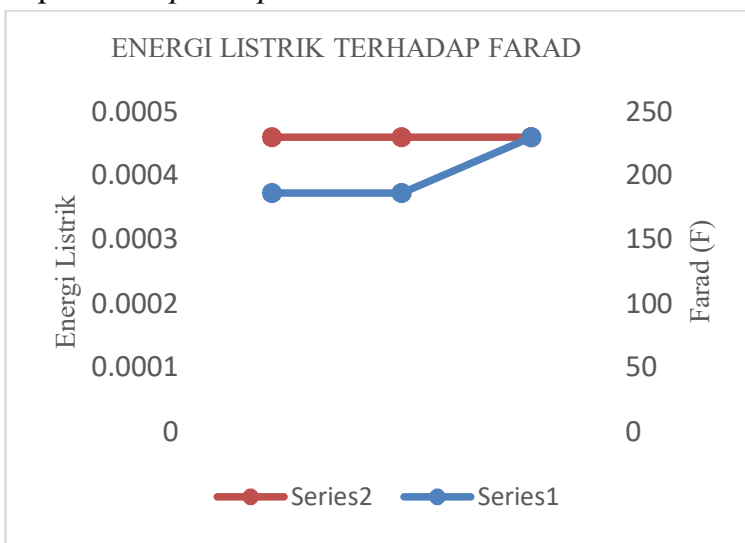

Gambar 3 Grafik Energi Listrik Terhadap nilai kapasitansi super kapasitor (farad)

Pada grafik di atas menunjukan kenaikan pada nilai energi terhadap kapasitansi super kapasitor, dari grafik dapat di lihat selisih yang sangat jauh dengan perbedaan $0.2 \mathrm{v}$. Pada grafik selanjutnya bisa di lihat perbedaan terhadap tegangannya seperti di grafik berikut.

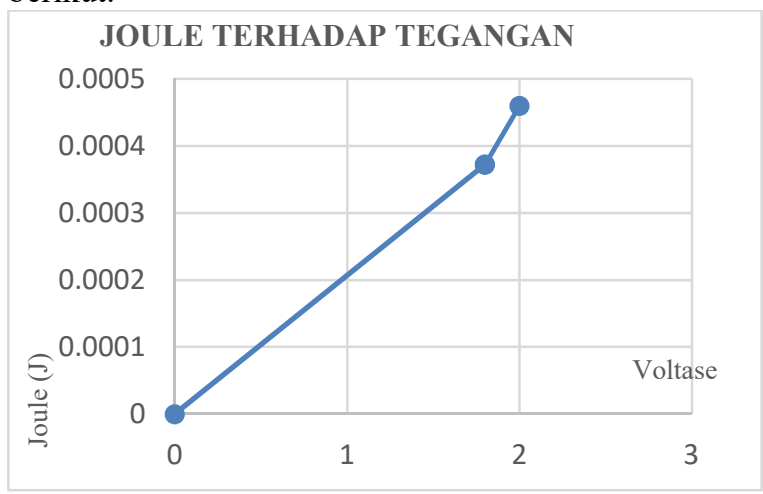

Gambar 4 Grafik joule terhadap tegangan (v)

Pada grafik diatas dapat di lihat tegangan naik berbanding lurus dengan nilai joule, dapat di simpulkan semakin besar tegangan maka semakin besar nilai joulenya di lihat dari grafik dengan perbedaan tegangan $0.2 \mathrm{v}$.

Pengujian Nilai Muatan Yang Tersimpan Pada Super kapasior Graphene

Pengujian ini adalah untuk mengethaui nilai $\mathrm{Q}$ atau muatan listrik pada super kapasitor graphene dengan sumber pengecasan yang sama di lihat dari tabel percobaan dimana tegangan sumber adalah $3 \mathrm{v}$ dari DC power supply. Untuk mencari nilai muatan listrik pada super kapasitor graphene adalah dengan persamaan :

$$
\begin{aligned}
& C=\frac{Q}{v}=\operatorname{sehing} g a=C \times V \\
& \mathrm{C}=\text { Kapasitansi }(\mathrm{F}) \\
& \mathrm{Q}=\text { Muatan listrik (Coulomb) } \\
& \mathrm{V}=\text { Tegangan Listrik (Volt) } \\
& Q=C \times V \\
& Q=230 \times 10^{-6} \times 3 \\
& Q=0.00069 \text { Coulomb }
\end{aligned}
$$

Pengujian Nilai Arus Yang Ada Pada Super Kapasitor Graphene

Pengujian ini untuk mengetahui berapa nilai arus yang ada di dalam super capasitor graphene dan juga mengetahui nilai joulenya, di lihat dari tabel percobaan 3.1 dengan persamaan :

$$
\begin{aligned}
& I_{1}=\frac{Q}{t} \\
& \mathrm{I}=\text { kuat arus listrik (A ampere) } \\
& \mathrm{Q}=\text { nuatan listrik (C columb) } \\
& \mathrm{t}=\text { waktu ( secon) }
\end{aligned}
$$


satuan kuat arus lainnya sebagi berikut :

a. Miliampere (mA), 1 mili Ampere $=10 x^{-3}$

b. Mikroampere $\mu \mathrm{A}, 1 \mu$ Ampere $=10 x^{-6}$

Percobaan 1

$$
\begin{aligned}
& I_{2}=\frac{Q}{t} \\
& I_{2}=\frac{0.00069}{60}=1.15 \times 10^{-5} \text { Ampere }
\end{aligned}
$$

Percobaan 2

$$
\begin{aligned}
& I_{2}=\frac{Q}{t} \\
& I_{2}=\frac{0.00069}{120}=5.75 \times 10^{-6} \text { Ampere }
\end{aligned}
$$

Percobaan 3

$$
\begin{aligned}
& I_{3}=\frac{Q}{t} \\
& I_{3}=\frac{0.00069}{3614.4}=2 \times 10^{-6} \text { Ampere }
\end{aligned}
$$

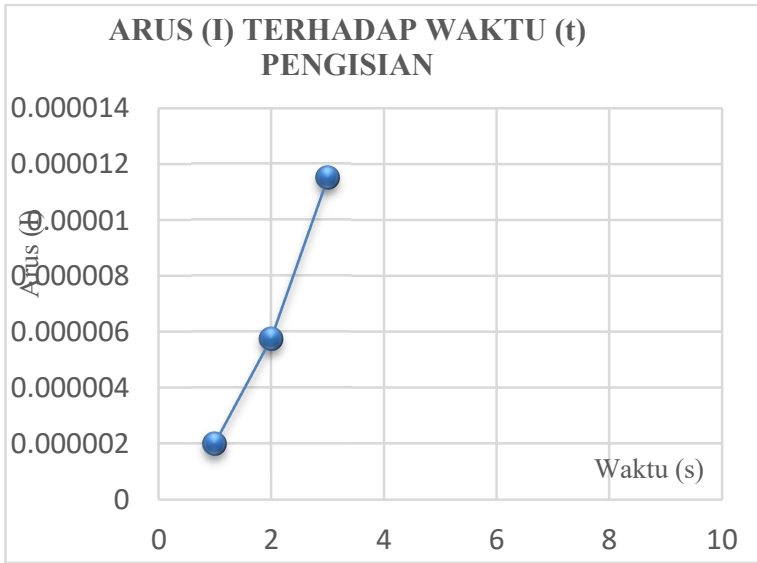

Gambar 5 Grafik arus terhadap waktu pengisian

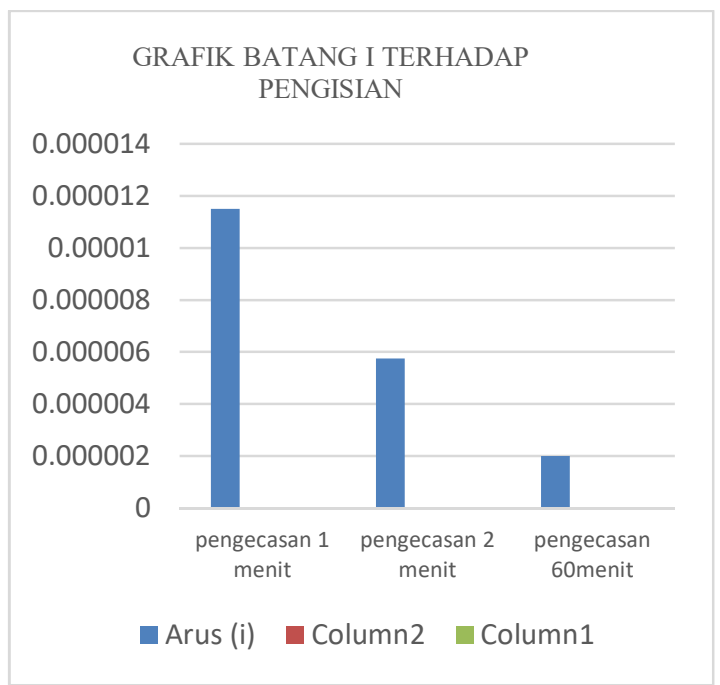

Gambar 6 Grafik batang arus terhadap waktu pengisian
Dari grafik di atas dapat kita lihat semakin lama pengecesannya maka arus yang mengalir akan semakin kecil di karena kan sifat konstan dari super kapasitor agar tidak terjadi panas yang berlebihan sesuai dengan kemampuan karbon aktif dan graphene. Pada awal pengecasan arus tidak stabil di lihat dari garis Y dari 5 sampai 0.00000115 dan mulai stabil di detik 120 di angka 0,00000575. Pengujian selanjutnya dengan mengecas super kapasitor sampai $60: 24$ menit dan di rubah ke detik sekitar 3614,4 detik, dari grafik di atas arus mulai menurun sampai sampai 5 garis ke bawah di angka 0,000002 dan pada saat itu juga arus stabil selama pengecasan. Dapat kita lihat lebih jelas di grafik batang semakin lama pengecasan semakin kecil arusnya yang di hasilkan tetapi semakin lama arus yang terbuang di lihat dari grafik.

\section{KESIMPULAN}

Berdasarkan penelitian yang telah di rencanakan dan di rancang dapat diperoleh beberapa kesimpulan, yaitu Perancangan material super kapasitor graphene pada penelitian ini menggunakan elektroda yang berbahan dasar dari graphene dan menggunakan karbon aktif, penggunaan karbon aktif supaya membantu graphene untuk meningkatkan daya serap yang tinggi untuk kapasitansi dan energi listrik, plat aluminium sebagai colektor, polyurethane sebagai perekat antara karbon dan plat aluminium tingkat kepadatan inilah yang mempengaruhi daya simpan muatan, phosporic acid sebagai elektrolit antara muatan positif dan muatan negatif, penggunaan phosporic acid ini adalah yang jenis food grade karena aman dan tidak terlalu asam apabila terkena tangan mau pun plat aluminium di bandingkan dengan yang teknis yang memiliki korosit yang tinggi juga sangat tidak aman bagi tangan.

Pembuatan graphene memiliki beberapa tahap salah satunya dengan menggunakan metode hummer's dengan takaran $25 \mathrm{ml} \mathrm{H} 2$ so4, 1 gr graphene, 3 gr kmno4, 150 air destilisai. Setelah graphene terbentuk penggunaan polyurethane sebagai perekat harus sesuai dengan takaran 2 mili polyurethane dan di campurkan dengan 1gr graphene. Setelah itu sebagai cairan elektrolitnya menambahkan $2 \mathrm{ml}$ phosporic acid ke separator dan nantinya akan di apid dua elektroda. Tingkat daya serap dari penelitian ini masih kecil tetapi memiliki daya pengecasan yang singkat. Dengan pengecasan 1 menit dan memiliki nilai capasitas $230 \mu \mathrm{F}$ dapat memuat tegangan sebesar $1,8 \mathrm{v}$ dan tegangan yang habis selama 3012.2 detik atau $50: 20,2$ menit, salama itu tegangan yang turun $0.0005 \mathrm{v} / \mathrm{s}$ dan tegangan yang terisi $0.0015 \mathrm{v} / \mathrm{s}$. Untuk memastikan dengan pengecasan selama 60 menit dan 
mendapat tegangan $2 \mathrm{v}$ dan tegangan yang habis selama 180 : 18,4 menit. Dapat di simpulkan semakin lama pengecasan maka semakin besar tegangan yang tersimpan dan semakin lama tegangan yang habis maka demikian dengan arus, dan energi listrik tersebut.

Untuk penelitian selanjutnya, penulis berharap ada penyempurnaan bahan dan campuran dengan menggunakan polyurethane jenis clear sebagai perekat antara elektroda graphene dan plat aluminium, menambahkan polyvinyl alcohol (PVA) pada phosporic acid supaya menetralisirkan asam pada phosporic acid sehingga aluminium tidak cepat korosit, juga melakukan sterilisai agar graphene memiliki kualitas yang jauh lebih tinggi, pemakuman di tambah dengan plastik film yang memiliki ketebalan $2 \mathrm{~mm}$ sebagai lapisan vakum yang terakhir supaya meminimalkan kebocoran, penggunaan bahan dan campuran harus di cek ke asliannya.

\section{DAFTAR PUSTAKA}

[1] Achmad Azmy Adhytiawan, Diah Susanti, (2013). "Pengaruh Variasi Waktu Tahan Hidrotermal terhadap Sifat Kapasitif Superkapasitor Material Graphene”. JURNAL TEKNIK POMITS Vol. 2, No. 1

[2] Afdhal Rizky, dkk, (2015). “Kebolehulangan (Reproduciblity) Dalam Pembuatan Sel Superkapasitor Dari Kayu Karet”. JOM FMIPA Volume 2 No. 1

[3] Andre K. Geim, (2011). "Nobel Lecture: Random walk to graphene”. REVIEWS OF MODERN PHYSICS, Volume 83

[4] Delebecq, dkk, (2013). "On the Versatility of Urethane/Urea Bonds: Reversibility, Blocked Isocyanate, and Non-isocyanate Polyurethane", Chemical Reviews. 113

[5] Dimitrios G. Papageorgiou, dkk, (2017). "Mechanical properties of graphene and graphene-based nanocomposites”. Journal of Elsevier. Progress in Materials Science

[6] Efelina, V, (2015). "Kajian Pengaruh Konsentrasi Urea dalam Sifat Optik Nanofiber Graphene Oxide/PVA (Polyvinil Alcohol) yang difbrikasi Menggunakan Teknik Electrospining”, Tesis. Yogyakarta : FMIPA UGM

[7] Farhadi, dkk, (2015). "Performance enhancement of actively controlled hybrid DC microgrid and pulsed power load". IEEE Trans. Ind. Appl. 51
[8] Fitria Puspitasari, dkk, (2014). "Efek variasi Waktu Ball Milling Terhadap Karakteristik Elektrokimia Sel SuperKapasitor Berbasis Karbon”. JOM FMIPA Volume 1 No. 2

[9] Genduk Alkurnia Wati, dkk, (2015). "Kapasitansi Elektroda Superkapasitor Dari Tempurung Kelapa”. Jurnal Fisika. Volume 04 Nomor 01

[10] Javni, dkk, (2013). "Polyurethanes from soybean oil, aromatic, and cycloaliphatic diamines by nonisocyanate route". Journal of Applied Polymer Science

[11] Ji-Lei shi, Dkk, (2014). "Hydrothermal reduction of three-dimensional graphene oxide for binder-free flexible supercapacitors". Electronic Supplementary Material (ESI) for Journal of Materials Chemistry A. Journal is The Royal Society of Chemistry

[12] Joko Murtono, Iriany, (2017). "Pembuatan Karbon Aktif Dari Cangkang Buah Karet Dengan Aktivator $\mathrm{H}_{3} \mathrm{PO}_{4}$ dan Aplikasinya Sebagai Penjerap Pb(II)", Jurnal Teknik Kimia USU, Vol. 6, No. 1

[13] Keren Zhang dkk, (2016). "Non-isocyanate poly(amide-hydroxyurethane)sfrom sustainable resources". Journal is The Royal Society of Chemistry. Green Chemistry

[14] K. S. Novoselove (2004). "Electric Field Effect in Atomically Thin Carbon Films" VOL 306 SCIENCE

[15] Maher F. El-Kady, Dkk, (2012). "Laser Scribing of High-Performance and Flexible GrapheneBased Electrochemical Capacitors". Science 335, 1326 DOI:10.1126/science.1216744

[16] Mariana olivia Esterlita, Netti Herlina, (2015). "pengaruh Penambahan Aktivator $\mathrm{ZnCl}_{2}, \mathrm{KOH}$, dan $\mathrm{H}_{3} \mathrm{PO}_{4}$ Dalam Pembuatan Karbon Aktif Dari Pelepah Aren (Arenga Pinnato”. Jurnal Teknik Kimia USU, Vol. 4, No. 1

[17] M. Farhadi and O. Mohammed,(2014). "Realtime operation and harmonic analysis of isolated and non-isolated hybrid DC microgrid". IEEE Trans. Ind. Appl., vol.50, no.4, pp.2900-2909

[18] Murugan Saranya, dkk, (2016). “Graphene-zinc oxide (G-ZnO) nanocomposite for electrochemical supercapacitor applications". Journal of Science: Advanced Materials and Devices

[19] Mody Lempang, (2014). "Pembuatan dan Kegunaan Arang Aktif”. Info teknis EBONI VOL. 11 No. 2 
[20] Nurhasni, dkk, (2012). "Penyerapan Ion Aluminium dan Besi dalam Larutan Sodium Silikat Menggunakan Karbon aktif”. Valensi Vol. 2 No. 4 (516-525)

[21] Nurlia Pramita Sari, dkk, (2017). "Boron Doped Grephene 3-Dimensi untuk Superkapasitor Kapasitas Tinggi”. Jurnal Rekayasa Mesin Vol.8, No.2

[22] Palaniselvam, dkk, (2015). "Graphene based 2Dmaterials for supercapacitors". Iop science. 2D Materials. 2: 032002.

[23] Quinlan RA, dkk, (2013). "Investigation of defects generated in vertically oriented graphene”. Elsevier Jurnal Carbon 64:92-100

[24] Rahman Faiz Suwandana, Diah Susanti, (2015). "Analisis Pengaruh Massa Redoktor Zinc terhadap Sifat Kapasitif Superkapasitor Material Graphene”. JURNAL TEKNIK ITS VOL. 4 No.

[25] Rajput, dkk, (2014). "Fatty acids based transparent polyurethane films and coatings". Progress in Organic Coatings. 77

[26] Sri Yanti, dkk, (2014). "Efek Modifikasi Permukaan Karbon Aktif Monolit Terhadap Sifat Fisi dan Elektrokimia Sel Superkapasitor". JOM FMIPA Volume 1 No. 2
[27] Teguh ariyanto, dkk, (2012). "Pengaruh Struktur pori Terhadap Kapasitansi Elektroda Superkapasitor Yang Dibuat Dari Karbon Nanopori”. Reaktor, Vol. 14 No. 1

[28] T. Zhu E., Ertekin, (2016). Generalized DebyePeierla/Allen-Feldman model for the lattice thermal conductivity of low-dimensional and disordered materials, Phys. Rev. 93

[29] T. Zhu, E. Ertekin, (2016). Phonons, localization and thermal conductivity of diamond nano threads and amorphous graphene, Nano Lett. 16

[30] Xiehong Cao, Dkk, (2014). "Three-dimensional graphene materials: preparation, structures and application in supercapacitors". journal is The Royal Society of Chemistry. Energy and Environmental Science

[31] Yang Gao, (2017). "Graphene and Polymer Composites for Supercapacitor Applications: a Review". Gao Nanoscale Research Letters 12:387 DOI 10.1186/s11671-017-2150-5

[32] Yu. M. Volfkovich, dkk (2012). "Studies of Supercapacitor Carbon Electrodes with High Pseudocapacitance". Recent Trend in Electrochemical Science and Technology, Dr. Ujjal Kumar Sur (Ed) 